\section{Comment}

These findings show a selective reporting bias to the Committee on Safety of Medicines, with general practitioners notifying a greater proportion of adverse reactions that are of greatest clinical concern. Our estimates are subject to potential reporting and recall biases. Some doctors who had submitted a yellow card may not have completed the green form. We would have underestimated the proportion of yellow cards submitted if green form responders were less likely to complete yellow cards than green form nonresponders. It seems more plausible that green form responders would be at least as likely to report yellow cards as green form non-responders. Doctors may not have indicated that a yellow card was submitted. As the number of yellow cards reported per doctor is low, the impact of recall bias on our estimates is probably limited. Our overall estimate of underreporting corresponds to previous estimates. ${ }^{5}$ The message that doctors should submit yellow cards for all suspected adverse drug reactions to "black triangle" drugs should be reinforced.

We thank the general practitioners who take part in prescription-event monitoring studies. We also thank Shayne
Freemantle and Gillian Pearce for technical help with accessing the data.

Contributors: RMM was involved in formulating the study hypothesis, executing and coordinating the study, study design, analysis and interpretation of data, and writing the paper. KVK was involved in interrogating the prescription-event monitoring database and preparing the data for analysis and contributed to the writing of the paper. LVW was involved in study design, discussion of core ideas, quality control, and interpretation of data and contributed to the writing of the paper. RDM initiated the research project, discussed core ideas, helped formulate the study hypothesis, participated in study design, was involved in interpretation of results, and edited the paper. RDM will act as guarantor.

Funding: None

Conflict of interest: None

Rawlins MD, Jefferys DB. United Kingdom product licence applications involving new active substances, 1987-1989: their fate after appeals. $B r$ I Clin Pharmac 1993;35.599-602.

2 Joint Formulary Committee. British national formulary. No 33. London: British Medical Association and Royal Pharmaceutical Society of Great Britain, 1997:10.

3 Bem JL, Mann RD, Rawlins MD. Review of yellow cards 1986 and 1987. BMJ 1988;296:1319.

4 Belton KJ, Lewis SC, Payne S, Rawlins MD, Wood SM. Attitudinal survey of adverse drug reaction reporting by medical practitioners in the United Kingdom. Br J Clin Pharmac 1995;39:223-6.

5 Lumley CE, Walker SR, Hall GC, Staunton N, Grob P. The under-reporting of adverse drug reactions seen in general practice. Pharmaceut Med 1986;1:205-12.

(Accepted 12 February 1998)

\title{
Neglect of growth and development in the clinical monitoring of children and teenagers with inflammatory bowel disease: review of case records
}

Subrata Ghosh, Hazel E Drummond, Anne Ferguson

Gastrointestinal Unit, Department of Medicine, Western General Hospital and University of Edinburgh, Edinburgh EH4 2XU Subrata Ghosh, consultant gastroenterologist Hazel E

Drummond, research associate

Anne Ferguson, professor of gastroenterology

Correspondence to: Professor Ferguson anne.ferguson@ ed.ac.uk

BMJ 1998;317:120-1
Failure of growth and retarded sexual development are serious and common problems in children and teenagers with inflammatory bowel disease, particularly Crohn's disease. Thus height, weight, sexual staging, and bone age should be closely monitored in such patients. In 1989 we reported serious underrecording of these variables of growth in a cohort of Scottish children with inflammatory bowel disease. ${ }^{1}$ We assessed the situation a decade later.

\section{Subjects, methods, and results}

We studied 28 boys and 13 girls aged $\leqslant 16$ years at first admission to hospital with ulcerative colitis $(n=14)$ or Crohn's disease $(n=27)$. These patients, identified from the Scottish hospitals database of inpatients statistics for 1984-88, were resident in four of the Scottish regions.

We reviewed the patients' case records and noted whether height, weight, bone age, and sexual development were recorded. The frequencies of recording of these variables of growth were analysed by specialty of consultant. Since $14(34 \%)$ of the patients were attending one consultant's (A) clinic, the frequencies of recording by this consultant were considered separately.
The table summarises the results. With the exception of consultant A, gastroenterologists, physicians, and surgeons made few recordings of height, and very few recordings of bone age or sexual development were made by any specialty, including paediatricians.

\section{Comment}

The causes of Crohn's disease and ulcerative colitis are unknown, but abundant evidence supports the clinical illness as being a composite effect of several variables both symptomatic and indolent. These include inflammatory disease activity, side effects of drugs, psychological distress, destructive ulceration, bone demineralisation, and growth failure. Growth failure is not confined to patients of paediatricians as growth and sexual maturation of young people with Crohn's disease often continue until age 20 or later. Despite this, few consultants in adult medicine or surgery record the physical development of teenage patients; perhaps the doctor assumes nothing specific can be done about growth failure, or this neglect may simply be an oversight.

We do not know if such neglect is unique to gastroenterologists, or whether similar findings would have emerged from studying the case records of teenagers with cancer, renal failure, asthma, rheumatic diseases, 
Recording of height, weight, bone age, and sexual development by consultants during hospital based care of young people with inflammatory bowel disease (mean follow up, 7.1 years)

\begin{tabular}{|c|c|c|c|c|c|c|c|c|}
\hline \multirow[b]{2}{*}{ Type of consultant } & \multirow[b]{2}{*}{$\begin{array}{c}\text { No of } \\
\text { consultants }\end{array}$} & \multirow[b]{2}{*}{$\begin{array}{c}\text { No of } \\
\text { patients }\end{array}$} & \multirow{2}{*}{$\begin{array}{l}\text { Median No of } \\
\text { visits per } \\
\text { patient (range) }\end{array}$} & \multirow[b]{2}{*}{$\begin{array}{l}\text { Total No } \\
\text { of visits }\end{array}$} & \multicolumn{2}{|c|}{ Median percentage of visits } & \multicolumn{2}{|c|}{ No of patients } \\
\hline & & & & & $\begin{array}{l}\text { Height recorded } \\
\text { (range) } \dagger\end{array}$ & $\begin{array}{l}\text { Weight recorded } \\
\text { (range) }\end{array}$ & $\begin{array}{c}\text { Bone age ever } \\
\text { recorded }\end{array}$ & $\begin{array}{c}\text { Sexual development } \\
\text { ever recorded }\end{array}$ \\
\hline Gastroenterologist (consultant A) & 1 & 14 & $23(11-39)$ & 313 & $51(16-67)$ & $92(63-100)$ & 12 & 13 \\
\hline General surgeon & 8 & 14 & $6(2-31)$ & 157 & $16(0-60)$ & $33(0-100)$ & 1 & 1 \\
\hline General physician & 6 & 7 & $13(3-30)$ & 105 & $22(0-67)$ & $89(14-100)$ & 0 & 3 \\
\hline Medical or surgical paediatrician & 7 & 17 & $19(3-56)$ & 386 & $89(6-100)$ & $93(12-100)$ & 1 & 3 (of 15 eligible) $\ddagger$ \\
\hline
\end{tabular}

*21 patients in care of more than one consultant.

†Some patients reached adult height.

$\ddagger$ Two patients aged $<10$ years were excluded.

or diabetes. A Royal College of Physicians Working Group on the transfer of young people with chronic physical disorders from paediatric to adult services has made 34 recommendations on health related aspects of transfer of care, ${ }^{2}$ but the recording of growth and pubertal status are not mentioned.

Nutritionists may argue that accurate clinical measurement is a cornerstone of knowledge of the physiology and pathology of growth. Clinical investigators may emphasise that research on the pathogenesis and treatment of growth failure in disease requires accurate historical as well as prospective data. Psychologists, and probably most clinicians, patients, and parents, may agree that a patient's problems cannot be understood fully without recognition and discussion of physical and sexual differences between patients and their peers. Thus we reiterate ${ }^{1}$ that consultants treating young people with inflammatory bowel disease need to be more aware of their patients' special nutritional and developmental problems, and should make regular measurements of the variables of growth.

Contributors: SG designed the study, collected, analysed, and interpreted the data, and prepared the paper. HED collected, analysed, and interpreted the data. AF designed the study, interpreted the data, and prepared the paper; she will act as guarantor for the paper.

We thank our medical colleagues for allowing us to examine their patients' records, and records' officers from hospitals throughout Scotland.

Funding: Clinical Research and Audit Group, Scottish Office.

Conflict of interest: None

1 Barton JR, Ferguson A. Failure to record variables of growth and development in children with inflammatory bowel disease. $B M J$ 1989;298:865-6.

2 Kurtz Z, Hopkins A (eds). Services for young people with chronic disorders in their transition from childhood to adult life. London: Royal College of Physicians, 1996:141-153.

(Accepted 7 January 1998)

\section{Words to the wise \\ Words that count}

It is possible to suffer simultaneously from acalculia and renal calculi, which is an odd state of affairs, on reflection. Both terms come from the Latin calculus, a small stone: a word that is formed by adding a diminutive ending to calx, the Latin word for chalk or limestone. Calx gives us our words calcium and calcine; but the os calcis, you may note, is not a particularly chalky bone. For reasons unknown, the Romans also used calx to mean "heel," and our word recalcitrant derives from that usage: it suggests a person who is liable to kick with their heels, like a mule.

But we should return to the little stones: they can be used to calculate, if they are laid out in a grid pattern to allow addition and subtraction. The Romans marked out such a counting grid on a table they called an abacus: a word we now apply to a rather different counting device. The counters we move around gaming boards originally had this more serious arithmetical function, and shop counters were originally ruled out in grids so that merchant and customer could calculate their bill. Exchequer comes to us from the French, but it has the same connotations: a place where calculations were carried out on a chequered board.

Our word number has, as you might expect, an ancient history. It can be traced back to the ancient Greek nemien, to distribute or to divide up. (Their goddess Nemesis, for instance, was in the justice distributing business.) This idea of distribution also gave the Greeks their word nomisma, for a type of coin. From that, the Romans got numerus, number, and nummus, a coin. So we now talk of numismatics, the study of coins, and nummular eczema, which is distributed in coin-like plaques.

But the Greeks must have derived nemien from a more ancient Indo-European root, for it has cousins in the north European tongues, such as the German nehmen and the Old English nim, both meaning "to take." The Old English verb is with us still: Nim is the name of an ancient coin game, in which players take turns at removing coins from a grid-like array. It is much loved by games theorists and all who followed Martin Gardner's "Mathematical Puzzles and Diversions" column in Scientific American. Numen, the past participle of nim, gives us our word numb; in this case, it is sensation that has been removed. And a nimble person is one who is adept at seizing and taking away whatever is available.

By 1600 , nim had fallen into disuse, except as a slang expression meaning "to pilfer," and Shakespeare used the word with this connotation. A modern audience can make a pretty good guess at the personalities of characters like Doll Tearsheet and Justice Shallow, but contemporaries could pick up other references that are now lost on us. When Master Slender accused Falstaff's cronies of stealing from his purse, Elizabethan attention would have turned immediately to that plausible rogue, Corporal Nym.

\section{Grant Hutchison, consultant anaesthetist, Dundee}

We welcome articles up to 600 words on topics such as A memorable patient, A paper that changed my practice, My most unfortunate mistake, or any other piece conveying instruction, pathos, or humour. If possible the article should be supplied on a disk. Permission is needed from the patient or a relative if an identifiable patient is referred to. We also welcome contributions for "Endpieces," consisting of quotations of up to 80 words (but most are considerably shorter) from any source, ancient or modern, which have appealed to the reader. 